\title{
Pileki Taşı'nın (İyidere, Rize) Geopolimer Üretiminde Kullanım Potansiyelinin Araştırılması
}

\author{
Investigation of the Potential of Pileki Stone (İyidere, Rize) for Geopolymer Cement \\ Production
}

\author{
Sevgi ÖZEN* \\ Recep Tayyip Erdoğan Üniversitesi, Mühendislik Fakültesi, Endüstriyel Tasarım Mühendisliği Bölümü, 53100, Rize
}

• Geliş tarihi / Received: 19.10.2018 • Düzeltilerek geliş tarihi / Received in revised form: 29.11.2018 • Kabul tarihi / Accepted: 14.12 .2018

\begin{abstract}
$\ddot{O} z$
Bu çalı̧manın sonuçları Rize ve çevresinde yöresel olarak rezerv veren Pileki Taşı esaslı geopolimer üzerinde yapılan deneylere dayanmaktadır. Pileki Taşı kullanılarak geopolimer üretim potansiyelinin araştırılması amacıyla $\mathrm{Na}_{2} \mathrm{SiO}_{3} / \mathrm{NaOH}$ oranı, hammadde/aktivatör oranı, kür sıcaklığı ve kür süresi gibi parametrelerin basınç dayanım üzerindeki etkileri incelenmiştir. Yapılan dayanım analizi sonuçlarına göre Pileki Taşı esaslı geopolimerin üretim potansiyeli bulunmaktadır. $\mathrm{Na}_{2} \mathrm{SiO}_{3} / \mathrm{NaOH}$ oranı 2 ve hammadde/aktivatör oranı 1.75 olan 28 günde $70^{\circ} \mathrm{C}$ sicaklıkta kuru kür yapılan karışım en yüksek basınç dayanım değerini vermektedir. Erken dayanım söz konusu olduğunda ise yüksek sıcaklıklarda kür yapılması ve $\mathrm{Na}_{2} \mathrm{SiO}_{3} / \mathrm{NaOH}$ oranının yüksek tutulması önerilmektedir. Ayrıca kür süresi arttıkça Pileki Taşı esaslı geopolimerlerin basınç dayanım değerlerinde düşüş tespit edilmiştir.
\end{abstract}

Anahtar kelimeler: Basınç dayanım, Geopolimer, Pileki Taşı

\begin{abstract}
The results of this study are based on experiments on geopolymer cement based Pileki Stone which gives local reserve in Rize and its surroundings. The effects of $\mathrm{Na}_{2} \mathrm{SiO}_{3} / \mathrm{NaOH}$ ratio, raw material / activator ratio, curing temperature and curing time on compressive strength were investigated in order to observe the potential production of Pileki Stonebased geopolymer cement. According to the results of the strength analysis, it is possible to produce the Pileki Stonebased geopolymer cement. $\mathrm{Na} 2 \mathrm{SiO} 3 / \mathrm{NaOH}$ ratio 2 and raw material / activator ratio of 1.75 in 28 days at $70{ }^{\circ} \mathrm{C}$ dry cure mixture gives the highest compressive strength value. In case of early resistance, it is recommended to cure at high temperatures and to keep the $\mathrm{Na} 2 \mathrm{SiO} 3$ / $\mathrm{NaOH}$ ratio high. In addition, as the curing time increased, the compressive strength values of Pileki Stone-based geopolymers were decreased.
\end{abstract}

Keywords: Compressive strength, Geopolymer, Pileki Stone

\footnotetext{
* Sevgi ÖZEN; sevgi.ozen@erdogan.edu.tr, Tel: (464) 22375 18; orcid.org/0000-0002-1875-3778
} 


\section{Giriş}

Doğu Karadeniz Bölgesi'nde el ile oyularak yapılan ekmek pişirme kaplarına Pileki adı verilmektedir. Bu kapları yapmak için kullanılan kayaçlara da Pileki Taşı adı verilmektedir. Siyah renkli, yayvan ve çanak biçimli Pileki kaplarının boyutları değişiklik gösterse de genellikle 25-35 $\mathrm{cm}$ çapında, 4-6 cm derinlikte ve 2-3 cm kalınlıkta olmaktadır (Kazancı ve Gürbüz, 2014). MÖ 2300'lü y1llardan son 30 yıla kadar, Doğu Karadeniz Bölgesi başta olmak üzere Kafkaslardan Balkanlara kadar oldukça geniş bir bölgede taş Pilekiler yaygın bir şekilde kullanılmaktayd1 (Uzun ve Uzun, 2001). Günümüzde ise Rize'nin İyidere ilçesinin Köşklü Köyü civarında bulunan insan yapımı pek çok taş ocağı arasından yalnızca bir tanesi turistik amaçla kullanılmaktadır. Mısır ekmeğine muazzam lezzet veren Pilekilerin üretimi ve kullanımı gelişen teknolojiyle birlikte yok denecek kadar azalmıştır.

Pilekiler çok uzun yıllardan beri Türk mutfak kültürüne yerleşmiş olsa da Geç Kretase yaşlı Pileki Taşı'nın litolojisi kısıtlı bir şekilde çalışılmıştır (Nazik vd., 2008; Şaroğlu vd., 2010). Genel itibariyle porfirik dokulu bazalt olarak isimlendirilen Pileki Taşı'nın ilk detaylı mineralojik karakterizasyon çalışması ise yalnızca bir kaynakta verilmiştir (Yıldız ve Özen, 2017). Aslında taş Pilekiler, mağaralar içerisinde bulunan yastık lav şeklinde yerleşen bazalt biriminden seçilip çıkarılan ve ardından şekillenen kaplardır. $\mathrm{Bu}$ mağaraların içerisinde bazalt dışında tüf ve aglomeralar da bulunmaktadır. Tüm bu kayaçlar, kalınlığ 1 ortalama 5000 metre olan Hemşindere Formasyonuna (Korkmaz ve Gedik, 1988) aittir. Bölgede yüksek miktarda rezerv veren, hem jeolojik miras niteliğinde hem de ticari bakımdan yüksek değere sahip olma potansiyeli olan Pileki Taşı'nın geopolimer yap1 malzemesi olarak kullanılabilirliğinin araştırılması bu çalışmanın ana konusunu oluşturmaktadır.

\section{Materyal ve Metod}

Çalışmada kullanılan Pileki Taşı, Rize'nin İyidere ilçesine bağlı Köşklü Köyü civarında bulunan Pileki Mağarası'ndan temin edilmiştir (Şekil 1). Örnek alımı birimin tüf ve bazalt kısmından alınmaya çalışılsa da baskın kayaç olarak tüf ağırlıklı olarak temin edilmiştir. Mağaradan yaklaşık $50 \quad \mathrm{~kg}$ kadar alınan el örnekleri laboratuvar ortamına getirilmiştir (Şekil 2). Malzemenin mağara içerisinde nemli olması dolayısıyla Pileki Taşı öğütme işleminden önce $50^{\circ} \mathrm{C}$ 'de 5 saat kadar kurutulmuştur. Daha sonra çeneli kırıcı ile yaklaşık $2 \mathrm{~cm}$ boyutuna getirilmiş, ardından bilyeli değirmen ile yaklaşık 1 saat kadar ögütülerek toz numune haline getirilmiştir. Pileki Taşı'nın oksit değerleri XRF yöntemi ile Recep Tayyip Erdoğan Üniversitesi Merkezi Araştırma Laboratuvarı'nda tayin edilmiştir. Blaine özgül yüzey alanı Recep Tayyip Erdoğan Üniversitesi Endüstriyel Yap1 Malzemeleri Laboratuvarı'nda yapılmıştır. Kayacın mineralojik faz içeriği ise kantitatif X-ray difraksiyon (QXRD) yöntemi ile Amerika'da bulunan Pittsburg Mineral and Environmental Technology Inc (PMET Inc.) laboratuvarında yaptırılmıştır.

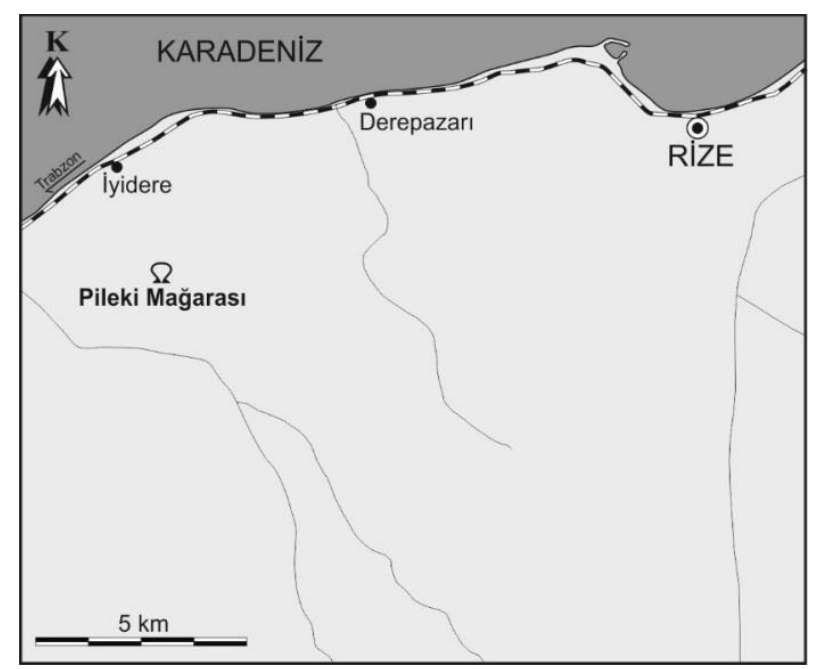

Şekil 1. Pileki Mağarası'nın yer bulduru haritası.

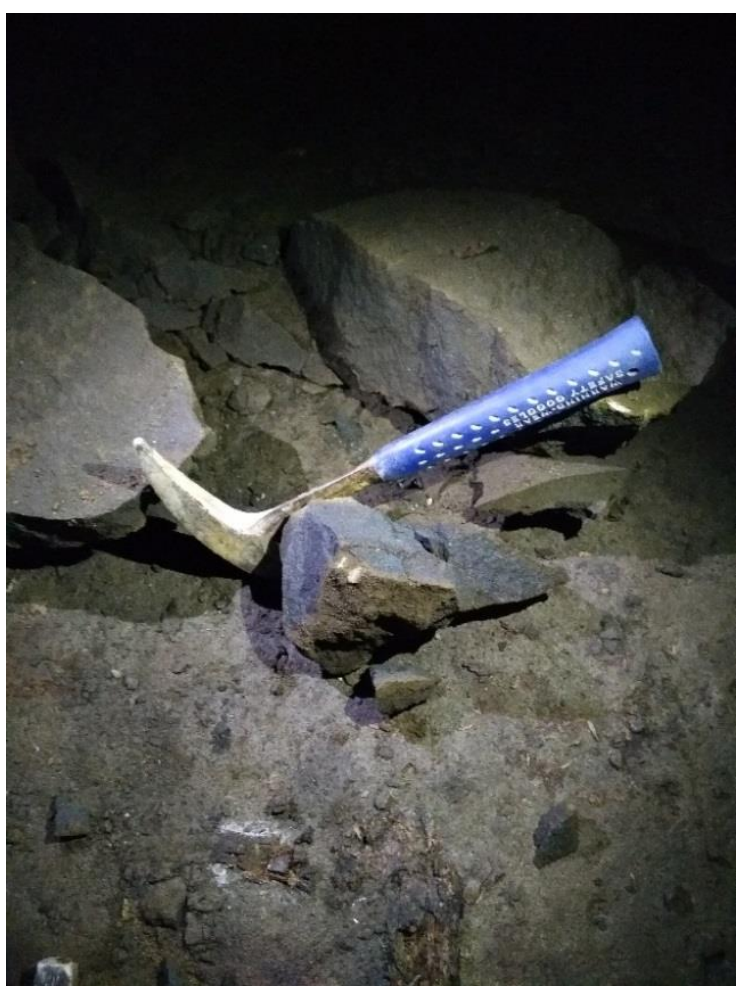

Şekil 2. Pileki Taşı'nın Pileki Mağarası'ndan temini. 
Pileki Taşı'nın aktivasyonu için sodyum hidroksit $(\mathrm{NaOH})$ ve sodyum silikat $\left(\mathrm{NaSiO}_{3}\right)$ olmak üzere iki farklı aktivatör kullanılmıştır. \%98 saflıktaki sodyum hidroksit pellet halinde, sodyum silikat ise $\left(\mathrm{SiO}_{2}=\% 27.7, \mathrm{Na}_{2} \mathrm{O}=\% 9.8, \mathrm{H}_{2} \mathrm{O}=\% 62.5\right)$ solüsyon halinde temin edilmiştir. Sodyum hidroksit $(10 \mathrm{M})$ solüsyonu, sodyum hidroksit pelletlerin damıtılmış suda çözülerek elde edilmiştir.

Karışım numunelerinin hazırlanması esnasında ilk olarak Pileki Taşı ve $\mathrm{NaOH}$ solüsyonu 2-3 dakika kadar karıştırılmıştır. Ardından karışıma $\mathrm{NaSiO}_{3}$ eklenmiş ve 3-5 dakika kadar daha karıştırılmıştır. Karışımlarda Pileki Taşı/aktivatör oranı olarak 1.75 ve $2, \mathrm{NaSiO}_{3} / \mathrm{NaOH}$ oranı olarak ise 2 ve 10 olarak seçilmiştir. Elde edilen karışım $5 \times 5 \times 5$ cm'lik küp kalıplara yerleştirilmiş, oda sıcaklığında bir gün bekletildikten sonra küp kalıplardan çıkarılarak etüvde $50^{\circ} \mathrm{C}$ ve $70^{\circ} \mathrm{C}$ olmak üzere iki farklı sıcaklıkta kür uygulanmıştır. Ardından basınç dayanım analizleri altı adet küp numunesi üzerinde 7, 28 ve 56 günlerde yapılmıştır.

\section{Bulgular ve Tartışma}

\subsection{Pileki Taşı’nın Karakterizasyonu}

Pileki Taşı'nın oksit değerleri Tablo 1'de verildiği gibidir. $\mathrm{SiO}_{2}$ ve $\mathrm{Al}_{2} \mathrm{O}_{3}$ değerlerinin toplamı \% 65.92'dir. Bu değer Davidovits (1994)'in tipik geopolimer reaksiyonu için önerdiği değer aralığındadır. Tablo incelendiğinde Pileki Taşı'nın $\mathrm{Na}_{2} \mathrm{O} \quad$ (\%5.27) değerinin yüksek olduğu görülmektedir. Kızdırma kaybı (LOI) ise 4.74 olarak saptanmıştır. Malzemenin Blaine özgül yüzey alanı $5720 \mathrm{~cm}^{2} / \mathrm{kg}^{\prime} \mathrm{dır}$.

Pileki Taşı'nın faz içerikleri Tablo 2'de sunulmuştur. Tablo incelendiğinde baskın mineral olarak Pileki Taşı'nın boşluklarında ikincil olarak oluşan zeolit minerallerinin olduğu (analsim ve klinoptilolit, \%33.4) görülmektedir. K-feldispat, plajioklas ve diopsit mineralleri majör miktarlarda bulunmaktadır. İkincil olarak oluşan kil minerali (vermikülit, \%2.9) ve volkan camı (\%4.7) ise minor miktardadır.

Tablo 1. Pileki Taşı'nın kimyasal özellikleri

\begin{tabular}{|ccccccccc|}
\hline \multicolumn{7}{|c|}{ Kimyasal Analiz (\%) } \\
\hline $\mathrm{SiO}_{2}$ & $\mathrm{Al}_{2} \mathrm{O}_{3}$ & $\mathrm{Fe}_{2} \mathrm{O}_{3}$ & $\mathrm{CaO}$ & $\mathrm{MgO}$ & $\mathrm{K}_{2} \mathrm{O}$ & $\mathrm{Na}_{2} \mathrm{O}$ & L.O.I. & Toplam \\
48.03 & 17.89 & 9.58 & 4.31 & 5.48 & 4.7 & 5.27 & 4.74 & 100 \\
\hline
\end{tabular}

Tablo 2. Pileki Taşı'nın kantitatif XRD analizi (QXRD)

\begin{tabular}{|l|cccccccc|}
\hline \multicolumn{10}{|c|}{ Mineralojik Kompozisyon (\%) } \\
\hline Mineral & K-feldispat & Plajioklas & Diopsit & Analsim & Klinoptilolit & Vermikülit & Volkan Camı & Toplam \\
Pileki Taş1 & 26.9 & 16.7 & 15.4 & 30.5 & 2.9 & 2.9 & 4.7 & 100 \\
\hline
\end{tabular}

Genel itibariyle silikat ya da alümina silikat içeren herhangi doğal ya da atık malzemenin geopolimerik reaksiyona katıldığı bilinmektedir. Ancak Pileki Taşı için geopolimerik reaksiyonu meydana getiren ana mineralin zeolit mineralleri (analsim ve klinoptilolit) olduğu düşünülmektedir.

\subsection{Parametrelerin Basınç Dayanım Üzerindeki Etkileri}

Bu çalışmanın ana konusu Pileki Taşı kullanılarak geopolimer elde edilip edilemeyeceğini araştırmak olduğundan farklı parametrelerin basınç dayanım üzerindeki etkisi incelenmiştir. Böylece Pileki Taşı için en uygun parametreler ile geopolimer üretimi saptanmış ve Pileki Taşı'nın bu doğrultuda kullanılabilirliğinin önü açılmış olacaktır. İncelenen parametreler geopolimerik reaksiyona etki eden dört ana parametreden $\mathrm{Na}_{2} \mathrm{SiO}_{3} / \mathrm{NaOH}$ oranı $(2,10)$, hammadde/aktivatör oran1 $(1.75,2)$, kür sicaklığ $1\left(50^{\circ} \mathrm{C}, 70^{\circ} \mathrm{C}\right)$ ve kür süresidir (7, 28 ve 56. gün). $\mathrm{Bu}$ parametreler kullanılarak elde edilen geopolimerlerin basınç dayanım değerleri Şekil 3'de verilmiştir.

Basınç dayanım değerlerine göre en yüksek dayanımı $(21 \mathrm{MPa})$ veren parametre 28 günlük, $70^{\circ} \mathrm{C}, \mathrm{Na}_{2} \mathrm{SiO}_{3} / \mathrm{NaOH} 2$, hammadde/aktivatör 1.75 olan sertleşmiş geopolimerdir (Şekil 3e). Aşağıda sırasılyla bu parametreler incelenmiştir. 


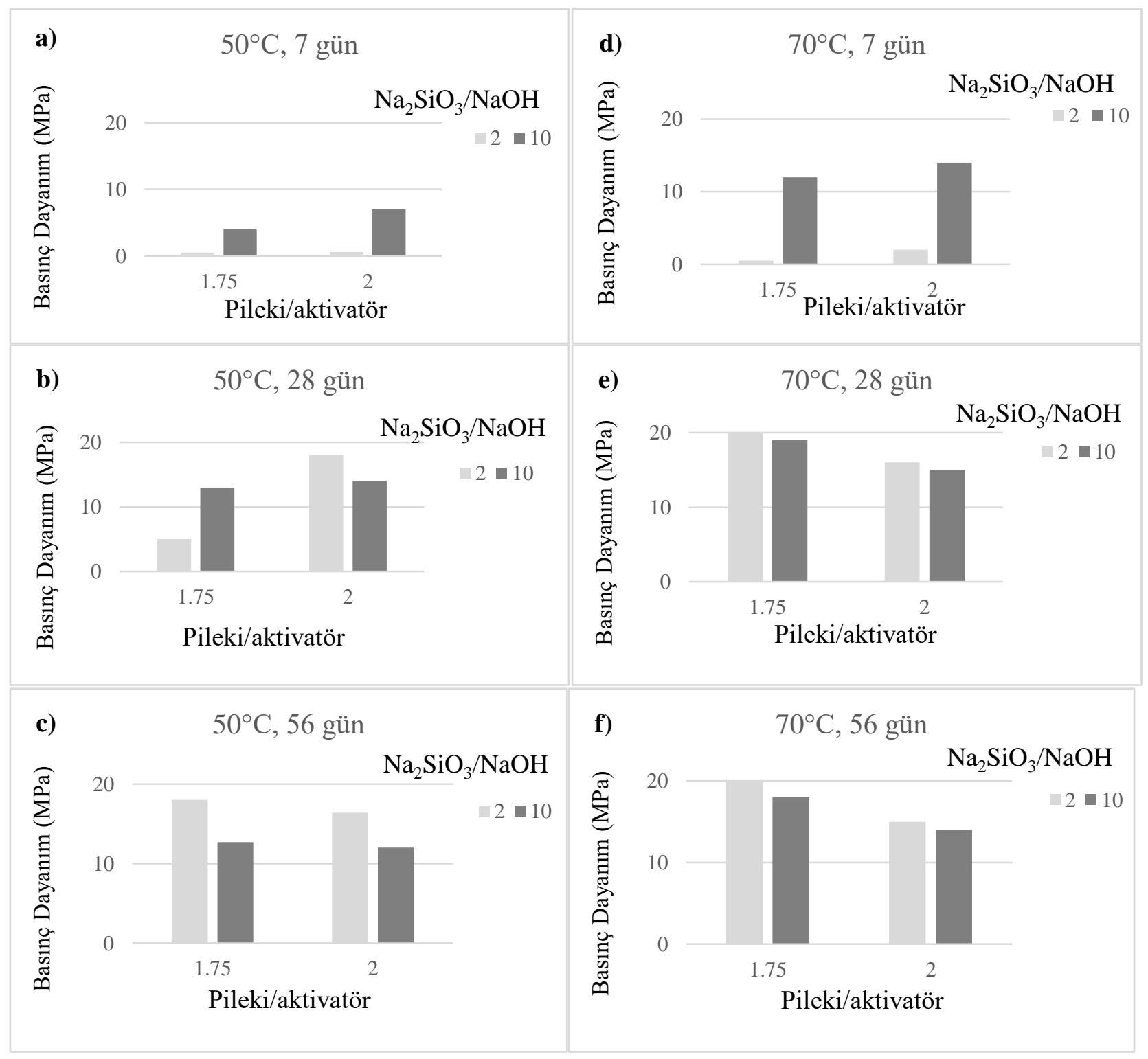

Şekil 3. Pileki Taşı esaslı geopolimerin basınç dayanım değerleri.

\subsection{1. $\mathrm{Na}_{2} \mathrm{SiO}_{3} / \mathrm{NaOH} \mathrm{Orant}$}

$\mathrm{Na}_{2} \mathrm{SiO}_{3} / \mathrm{NaOH}$ oranı geopolimerler açısından önemli parametrelerden biridir. $\mathrm{Na}_{2} \mathrm{SiO}_{3} / \mathrm{NaOH}$ oranının dayanıma etkisini incelemek amacıyla 2 ve 10 değerlerine sahip karışımların basınç dayanım gelişimleri incelenmiştir. 7 günlük geopolimerler açısından $\mathrm{Na}_{2} \mathrm{SiO}_{3} / \mathrm{NaOH}$ oran 10 olan sertleşmiş geopolimerler daha yüksek dayanım değerleri (4-14 MPa) vermiştir (Şekil $3 \mathrm{a}, \mathrm{d}) .28$ ve 56 günlük geopolimerler açısından ise s1caklığa bağlı olmaksızın $\mathrm{Na}_{2} \mathrm{SiO}_{3} / \mathrm{NaOH}$ oran1 2 olan geopolimerler daha yüksek mukavemet vermişlerdir (Şekil 3b,c,e,f).

$\mathrm{Bu}$ bilgiler 1şı̆̆ 1 altında malzemenin erken dayanım kazanması için $\mathrm{Na}_{2} \mathrm{SiO}_{3} / \mathrm{NaOH}$ oranının yüksek tutulması gerekliliği sonucu çıkmaktadır.
Ancak en yüksek basınç değerleri geç dayanımlar ile elde edilmiştir.

\subsubsection{Hammadde/Aktivatör Oranı}

7 günlük dökümler için sıcaklığa bağlı olmaksızın hammadde/aktivatör oran1 2 olan geopolimerler daha yüksek dayanım değerleri vermektedir (Şekil $3 \mathrm{a}, \mathrm{d})$. 28 günlük dökümler için ise $50^{\circ} \mathrm{C}$ ' de hammadde/aktivatör oranı 2 (18 MPa), $70^{\circ} \mathrm{C}$ 'de hammadde/aktivatör oranı 1.75 (21 MPa) daha iyi dayanım değerleri vermiştir. 56 günlük dökümler için ise sıcaklığa bağlı olmaksızın hammadde/aktivatör oranı 1.75 daha iyi mukavemet değerleri vermiştir (Şekil 3c,f). Ancak en yüksek basınç dayanım değerleri hammadde/aktivatör oranı 1.75 olan sertleşmiş geopolimerler ile elde edilmiştir (Şekil 3e). 


\subsubsection{Kür sıcaklı̆̆ı}

Alkaliler ile aktive edilmiş geoplimerlerin dayanım kazanmaları için çoğunlukla belli sıcaklık değerlerinde kuru kür yapılması gerekmektedir. $\mathrm{Bu}$ tür yeni nesil bağlayıc1 malzemeler oda sıcaklığında kürlendiğinde ise genellikle dayanım kazanamamaktadır. Ayrıca kür sıcaklığ 1 olarak genellikle $40^{\circ} \mathrm{C}$ ile $90^{\circ} \mathrm{C}$ arasındaki değerler seçilmektedir (Davidovits, 1994). Bu değer aralığında sicaklık ne kadar artarsa geopolimer o kadar hizlı dayanım kazanmaktadır. Genel itibariyle düşük kür sıcaklıklarında malzeme aktif olamamakla birlikte, yüksek sıcaklıklarda ise hızlı nem kaybından dolayı oluşan çatlaklar dolayısıyla sertleşmiş geopolimer kırılip parçalanabilmektedir. Tüm bu bilgiler ışığı altında Pileki Taşı'nın en yüksek dayanım değerini bulmak için genel geçerliliği olan $50^{\circ} \mathrm{C}$ ve $70^{\circ} \mathrm{C}$ olarak iki sıcaklık değeri seçilmiştir. Yapılan analizler neticesinde $50^{\circ} \mathrm{C}^{\prime}$ de 7 günlük geopolimerlerin dayanımlarının düşük olduğu saptanmıştır (Şekil 3a). $70^{\circ} \mathrm{C}$ 'de 7 günlük geopolimerlerin ise belli bir dayanım değerlerine (10-15 MPa civarı) ulaştığı görülmektedir (Şekil 3d). Elde edilen bu verilere dayanarak geopolimerlerin erken dayanımı için yüksek sıcaklık değerlerine ihtiyaç duyulduğunu söylemek mümkündür. 28 ve 56 günlük geopolimerler için ise $50^{\circ} \mathrm{C}$ 'nin de belli bir dayanıma ulaşmak için yeterli olduğunu görmekteyiz. Ancak $70^{\circ} \mathrm{C}^{\prime}$ lik geopolimerlerin daha yüksek basınç dayanım değerlerine ulaşması Pileki Taşı için yüksek sıcaklıkların yüksek dayanım elde etmek için daha uygun olduğunu göstermektedir (Şekil 3d,e,f).

\subsubsection{Kür Süresi}

Portland çimentosunda olduğu gibi geopolimerler için de kür süresi arttıkça dayanım değerleri artmaktadır. Şekil 3'den de anlaşıldığı üzere 7 günlük dökümler ile belli bir dayanım değerine ulaşan geopolimerler, en yüksek dayanım değerlerine 28 günlük geopolimerler ile ulaşılmıştır. $\mathrm{Bu}$ noktadan sonra ise dayanım değerlerinde çok az miktarda da olsa düşüş tespit edilmiştir. Dayanım değerlerindeki bu düşüşün nedeni sıcaklıkla ilişkilidir. Etüvde kuru şekilde kürlenen numunelerde belli bir gün sınırını aştıktan sonra nem kaybından dolayı kırıklar ve çatlaklar oluşmaktadır. Elde edilen geopolimerlerin dayanımları artsa bile numunelerde bulunan çatlaklar dolayısıyla numuneler parçalanabilmektedir.

\section{Sonuç ve Öneriler}

$\mathrm{Bu}$ araştırmadan çıkan sonuçlar ve ileriki çalışmalar için öneriler aşağıda sunulduğu gibidir:

- Rize ve çevresinde yüksek rezerv veren Pileki Taşı, geopolimer üretimi açısından uygundur.

- Basınç dayanım değeri en yüksek olan Pileki Taşı esasl 1 geopolimer $\mathrm{Na}_{2} \mathrm{SiO}_{3} / \mathrm{NaOH}$ oranı 2 ve hammadde/aktivatör oranı 1.75 olan 28 günde $70^{\circ} \mathrm{C}$ sicaklıkta kuru kür yapılan karıșımdır.

- Pileki Taşı esaslı geopolimerin erken dayanım kazanması için yüksek sıcaklıklarda kür yapılmas1 ve $\mathrm{Na}_{2} \mathrm{SiO}_{3} / \mathrm{NaOH}$ oranının yüksek tutulması önerilmektedir.

- Kür süresi arttıkça Pileki Taşı esaslı geopolimerlerin basınç dayanım değerlerinde az miktarda düşüş tespit edilmiştir.

- Dayanım değerlerinin sunulan çalışmaya oranla arttırmak için $\mathrm{KOH}, \mathrm{K}_{2} \mathrm{SiO}_{3}$ gibi solüsyonlar ileriki çalışmalar için öneriler arasındadır.

\section{Kaynaklar}

Davidovits, J. 1994. Properties of geopolymer cements. In: First International Conference on Alkaline Cements and Concretes, Kiev, Ukraine. Pp. 131-149.

Kazanc1, N. ve Gürbüz, A., 2014. Jeolojik Miras Nitelikli Türkiye Doğal Taşları. Türkiye Jeoloji Bülteni, Cilt 57, Sayı 1.

Korkmaz, S. ve Gedik, A., 1988. Rize-Fındıkl1Çamlıhemşin arasında kalan bölgenin jeolojisi ve petrol oluşumları. Jeoloji Mühendisliği, 32$33,5-15$.

Nazik, L. Savaş, F. Kahraman, İ. Acar, C., 2008. Pileki Mağarası (Taşhane) İyidere- Rize araştırma raporu. Maden Tetkik ve Arama Genel Müdürlüğü, Rapor no 11012.

Şaroğlu, F., Güner, Y., Nazik, L., Aksoy, B., 2010. Pileki mağarası ve jeokültürel değeri. 1. Uluslararası Jeolojik Koruma Sempozyumu ve Güneydoğu Avrupa Ülkeleri ProGEO Toplantısı (15-19 Eylül 2010, Firat Üniversitesi, Elazığ) Bildiri Özetleri, s. 34-35.

Uzun, A. ve Uzun, S. 2001.Taşhaneden aşhaneye: Taş Pilekiler. Osmangazi Üniversitesi Sosyal Bilimler Dergisi Say1 2.

Yıldız, E. ve Özen, S. 2017. Pileki Taşı'nın mineralojik, petrografik ve jeokimyasal özellikleri. TÜBITAK, Proje No: 919B011503088. 